\title{
Comparison of the Efficacy and Safety of Flunarizine to Propranolol in the Prophylaxis of Migraine
}

\author{
M.J. Gawel, J. Kreeft, R.F. Nelson, D. Simard and W.S. Arnott
}

\begin{abstract}
This study was designed to compare flunarizine, a cerebro-specific calcium channel antagonist, and propranolol in the prophylaxis of migraine with or without aura. Following a 1 month single-blind placebo baseline period, 94 patients were equitably randomised under double-blind conditions to take flunarizine $10 \mathrm{mg}$ daily or propranolol $80 \mathrm{mg}$ twice daily for 4 months. Both treatments led to a significant reduction in the frequency of migraines and use of rescue analgesics with a significantly greater decrease in number of attacks for flunarizine after 1 and 4 months. Neither treatment affected the severity nor duration of migraines. Overall, $67 \%$ of flunarizine patients and $51 \%$ of propranolol patients responded positively. Propranolol significantly reduced blood pressure and heart rate; flunarizine had no effect on cardiovascular function. Weight gain was noted with both treatments. Flunarizine is at least as effective as propranolol in the prophylactic treatment of migraine and may have a better safety profile.
\end{abstract}

RÉSUMÉ: Comparaison en double insu de l'efficacité et de la sécurité de la flunarizine, un antagoniste des canaux calciques spécifique au SNC, dans le traitement prophylactique de la migraine. Cette étude a été conçue pour comparer la flunarizine, un antagoniste des canaux calciques à spécificité cérébrale, et le propranolol dans la prophylaxie de la migraine avec ou sans aura. À la suite d'une période placebo en simple insu servant de ligne de base, 94 patients ont été randomisés équitablement en double insu au traitement par la flunarizine $10 \mathrm{mg}$ par jour ou par le propranolol $80 \mathrm{mg}$ deux fois par jour pour 4 mois. Les deux traitements ont produite une diminution significative de la fréquence des migraines et de l'utilisation d'analgésiques le cas échéant, avec une diminution significativement plus considérable du nombre des crises sous traitement à la flunarizine après 1 et 4 mois. Aucun des traitements n'a influencé la sévérité ou la durée des crises. Dans l'ensemble, $67 \%$ des patients recevant la flunarizine et $51 \%$ des patients recevant le propranolol ont eu une réponse favorable. Le propranolol a diminué significativement la tension artérielle et le rythme cardiaque; la flunarizine n'a pas eu d'effet sur la fonction cardiovasculaire. Un gain de poids a été constaté avec chacun des deux traitements. La flunarizine est au moins aussi efficace que le propranolol dans le traitement prophylactique de la migraine et a peut-être un meilleur profil de sécurité.

Can. J. Neurol. Sci. 1992; 19: 340-345

Prophylactic pharmacotherapy of migraine is indicated in patients in whom the frequency and/or severity of migraine attacks persistently disrupt the patient's daily functioning despite use of effective treatment in acute attacks and the institution of appropriate nonpharmacological approaches.' Although this migraine profile describes approximately one-third or less of migraineurs, this type of headache sufferer may represent a large proportion of the headache practice of a neurologist. ${ }^{2}$

Of the array of prophylactic agents available, none is universally effective nor well-tolerated and research continues in this area to identify an agent with maximal efficacy and a minimal side effect. Currently in North America, propranolol is the most commonly prescribed medication for this indication. ${ }^{1}$ The prophylactic utility of propranolol is limited, however, by its con- traindications (asthma, insulin-dependent diabetes) and its side effect profile, which includes potentially dangerous cardiovascular effects. ${ }^{3}$

Recently, calcium channel antagonists have received increasing attention as alternative medications for migraine prophylaxis. ${ }^{4.5}$ In Canada, several such agents are commercially available and have been investigated for the prophylaxis of migraines, however, only flunarizine has been approved for this indication. ${ }^{6}$

Flunarizine is a difluorinated piperazine derivative designated as a class IV calcium antagonist according to the WHO classification system. ${ }^{7}$ It is structurally and pharmacodynamically similar to cinnarizine. Flunarizine does not interact with cardiovascular slow calcium channels and consequently does not affect cardiovascular function. By virtue of its ability to cross the

From the Division of Neurology, Sunnybrook Health Sciences Centre, Toronto, (M.J.G.); Headache Clinic, Victoria Hospital, London (J.K.); Division of Neurology, Ottawa General Hospital, Ottawa (R.F.N.); Department of Neurology, Hôpital de l'Enfant-Jésus, Québec City (D.S.); Research and Development, Janssen Pharmaceutica Inc., Mississauga (W.S.A.)

Received November 18, 1991. Accepted in final form March 9, 1992

Reprint requests to: M.J. Gawel, MD FRCP(C), Sunnybrook Health Sciences Centre, Room E425, 2075 Bayview Avenue, Toronto, Ontario, Canada M4N 3 M5 
blood-brain barrier, flunarizine's activity is selective for central nervous system calcium channels. Pharmacological studies have generated several hypotheses for the mechanism of flunarizine's possible beneficial effect in the treatment of migraine: inhibition of vasospasm in cerebral blood vessels, direct cellular inhibition of hypoxia, prevention of vasoconstriction, normalisation of abnormal central serotoninergic nerve activity, and improved blood viscosity and erythrocyte deformability. ${ }^{8.9}$

Several well-controlled, double-blind, randomised clinical trials against placebo and active agents have demonstrated flunarizine's activity in this patient population. ${ }^{10-16}$ However, its efficacy and safety as a prophylactic agent for migraines has not been systematically evaluated against the current standard of therapy, propranolol, at doses recommended in the product monographs in order to reflect adequately current prescribing practices in Canada.

The present study was designed to determine the comparative efficacy and safety of flunarizine $10 \mathrm{mg}$ o.d. and propranolol $80 \mathrm{mg}$ b.i.d. in the prophylaxis of migraine headaches.

\section{Methods}

The study was conducted at four Canadian centres. Ethics Committee approval of the protocol was obtained at each centre and all patients signed informed consent prior to enrolment.

\section{Patients}

Male and female outpatients aged 18 - 65 years with a documented history of migraine attacks were eligible for entry into the trial. For inclusion, candidates had to experience between two and eight migraine headaches (as defined by the World Federation of Neurology Research Group in Migraine and Headache) per month. Criteria for exclusion from this study were: non-migrainous headache, previous unresponsiveness to more than two antimigraine prophylactic drugs, pregnancy or lactation, asthma, depression or significant cardiovascular, renal or hepatic disease. Patients were required to discontinue ongoing prophylactic therapy at least one week prior to enrolment and may not have received propranolol in the previous six months.

\section{Treatment Plan}

Patients were initially randomised to one of two parallel double-blind active treatment groups: flunarizine or propranolol. A one month single-blind placebo washout and baseline period preceded the four month active treatment phase. The dosage of double-blind study medication was initially titrated in fixed increments to the maintenance dose. Patients assigned to propranolol were titrated as follows: day 1 (40 mg qhs), day $3(40 \mathrm{mg}$ bid), day 5 ( $40 \mathrm{mg}$ qam $+80 \mathrm{mg}$ qhs), day 8 ( $80 \mathrm{mg}$ bid) (maintenance dose). Patients randomised to flunarizine received $5 \mathrm{mg}$ qhs for the first 6 days followed by $10 \mathrm{mg}$ qhs thereafter (maintenance dose). The double-dummy technique was employed to maintain the blind with twice and once daily dosing regimens; patients assigned to flunarizine received a placebo capsule qam.

Patients were assessed monthly. Daily diaries were used by patients to record the number of migraine attacks, the pain severity on a scale of 1 (mild) to 10 (excruciating) and the duration of attack (hours). Patients also recorded any rescue medication (analgesic) use as well as the occurrence of any adverse experience(s) on a daily basis. Diary data were summarised monthly. The "headache unit index", defined as the average number of attacks per day, was calculated from diary data. In the clinic, patients were questioned with respect to changes in alcohol and tobacco consumption as well as diet and lifestyle changes. A global evaluation of study medication efficacy on a 6-point categorical scale was conducted at the end of the study period by both physician and patient.

Safety assessments included routine biochemistry, haematology and urinalysis at baseline and after 2 and 4 months of active treatment. Vital signs (blood pressure, heart rate and weight) were obtained at each visit. Blood pressure and heart rate were recorded by an independent third party, uninvolved in patient management or in the assessment of symptoms, in order to prevent unblinding due to the known cardiovascular effects of propranolol. Adverse experiences reported were recorded at each visit.

\section{Statistical Analysis}

The comparability of treatment groups for demographic and baseline parameters was assessed with the unpaired t-test for continuous parameters and Pearson's Chi Square or Fisher's Exact test as appropriate for categorical variables.

Analysis of efficacy data and vital signs was conducted on eligible patients. Availability of baseline data plus one postwashout on-treatment evaluation was set as the criterion for efficacy evaluability. Analysis of laboratory parameters and adverse experiences was by the intention-to-treat method.

Two efficacy parameters were designated as primary: migraine attack frequency (days with headache and number of attacks) and average attack intensity. All other parameters were considered secondary: headache unit index (number of attacks per day), attack duration, end-of-treatment patient global evaluation, and analgesic use.

A between-treatment, across-time analysis was conducted using the 3 factor repeated measures analysis of variance (ANOVA). Pairwise comparisons were performed between the two treatments at months $1,2,3$ and 4 using the least square estimate; appropriate Bonferroni adjustment for multiple comparisons was made to alpha $\left(\alpha^{\prime}=0.0125\right)$.

A within-treatment assessment was performed using an endpoint analysis at both the last evaluable and final (completers) visits to determine the true treatment outcome of the trial by providing clinically worst- and best-case scenarios respectively. The one-way ANOVA of difference from baseline scores to test the hypothesis of no treatment effect was employed for this purpose. Where within-treatment effects were identified, subsequent analysis of between-treatment change from baseline was performed with the one-way ANOVA. Where baseline differences necessitated the inclusion of baseline values as covariates, the repeated measures LS Means were adjusted using an extension procedure by Miles-McDermott. ${ }^{17}$.

The percentages of responders and nonresponders based on the global evaluation of treatment by patients were compared between treatments with the Fisher's Exact test. A responder was defined as a global evaluation of "excellent" or "good". The mean numbers of doses of relief medication were analysed for between treatment differences using the non-parametric Wilcoxon Rank Sum test at each visit with Bonferroni adjusted alpha.

Analysis of laboratory parameters and adverse experiences was descriptive only. Treatment-dependent trends in laboratory 
abnormalities and frequency/severity of adverse experiences were emphasised.

\section{RESULTS}

A total of 94 patients was randomised with equitable distribution between treatments: flunarizine $(n=46)$, propranolol $(n=48)$.

The two treatment groups were statistically similar with respect to demographic and migraine history parameters (Table 1). The patient population was predominantly female $(90.4 \%)$ and the average patient age was 35.7 years. On average, patients reported a history of migraines for over 16 years and had experienced 4.7 attacks per month for the previous month with an average intensity of 7.7 on a scale where 10 was the most severe. The primary diagnosis was migraine with aura in $39.4 \%$ and migraine without aura in $60.6 \%$ of patients.

Of the 94 randomised patients, five (5.3\%) were excluded from efficacy analyses as they withdrew from the trial during the baseline evaluation period and therefore failed to contribute post-washout data on active treatment. Thus 89 patients (flunarizine $n=44$, propranolol $n=45$ ) were considered in the efficacy analysis. The majority of patients $(84 \%)$ in each treatment group completed the four month active treatment phase. Patient attrition is summarised in Table 2. Both treatments resulted in a significant reduction in the primary endpoint of migraine frequency as indicated by within-treatment analysis of the number of migraine attacks $(p<0.0001)$ with the flunarizine group reporting significantly fewer attacks during months 1 and $4(\mathrm{p}<0.01)$ (Figure 1). The derived parameter headache unit index followed this same pattern of results. The percentage reduction in attack frequency at termination was $49 \%$ and $25 \%$ in the flunarizine and propranolol groups respectively. Additionally, each treatment was associated with a significant reduction in days per month with migraine $(p<0.001)$ (Figure 2$)$; the extent of reduction with flunarizine $(45 \%)$ was greater than that with propranolol (29\%), though this did not reach statistical significance.

Neither treatment affected severity nor duration of migraine attacks although a trend towards reduction of both factors was observed in each treatment group (Tables 3,4 ).

Table 1: Demographics of the Study Population

\begin{tabular}{lcc}
\hline \hline Parameter & Flunarizine & Propranolol \\
\hline Sex: Fernale & 42 & 43 \\
$\quad$ Male & 4 & 5 \\
$\begin{array}{l}\text { Age (years) } \\
\text { (Mean } \pm \text { SD) }\end{array}$ & $37.2 \pm 8.3$ & $34.7 \pm 8.7$ \\
$\begin{array}{l}\text { Height (m) } \\
\text { (Mean } \pm \text { SD) }\end{array}$ & $1.63 \pm 0.11$ & $1.60 \pm 0.10$ \\
$\begin{array}{l}\text { Weight (kg) } \\
\text { (Mean } \pm \text { SD) }\end{array}$ & $64.48 \pm 13.74$ & $63.27 \pm 13.27$ \\
$\begin{array}{l}\text { Diagnosis: Classic } \\
\text { Common }\end{array}$ & 17 & \\
$\begin{array}{l}\text { Age at Onset (years) } \\
\text { (Mean } \pm \text { SD) }\end{array}$ & $20.2 \pm 9.4$ & 20 \\
$\begin{array}{l}\text { Avg. Attack Frequency } \\
\text { Last 3 months } \\
\text { (Mean } \pm \text { SD) }\end{array}$ & $4.6 \pm 1.8$ & $17.7 \pm 8.0$ \\
$\begin{array}{l}\text { Avg. Attack Severity } \\
\text { Last 3 months } \\
\text { (Mean } \pm \text { SD) }\end{array}$ & $7.7 \pm 1.7$ & $4.8 \pm 2.1$ \\
\hline
\end{tabular}

At termination, $67 \%$ of patients assigned to flunarizine assessed themselves as responders compared to $51 \%$ of propranolol treated patients; this difference did not reach statistical significance. In patients with a diagnosis of migraine with aura, response rates were $59 \%$ and $61 \%$ in the flunarizine and propranolol groups respectively. In patients with migraine without aura, the respective response rates were $73 \%$ and $44 \%(p=0.035)$.

A significant reduction in rescue analgesic doses required while on active study medication was found in both treatment

Table 2: Patient Attrition

\begin{tabular}{lcc}
\hline \hline Time in trial & \multicolumn{2}{c}{ Number of patients } \\
Plunarizine & Propranolol \\
\hline Enrolment & 46 & 48 \\
Baseline & 44 & 45 \\
Month 1 & 44 & 45 \\
Month 2 & 43 & 43 \\
Month 3 & 40 & 40 \\
Month 4 & 37 & 39 \\
\hline
\end{tabular}

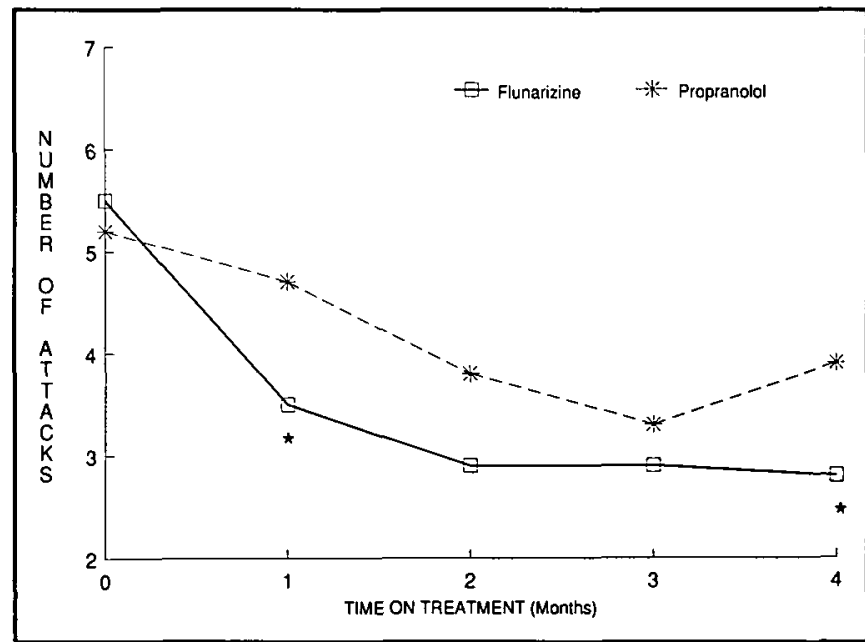

Figure I - Mean number of migraine attacks.

* statistically significantly fewer attacks for flunarizine.

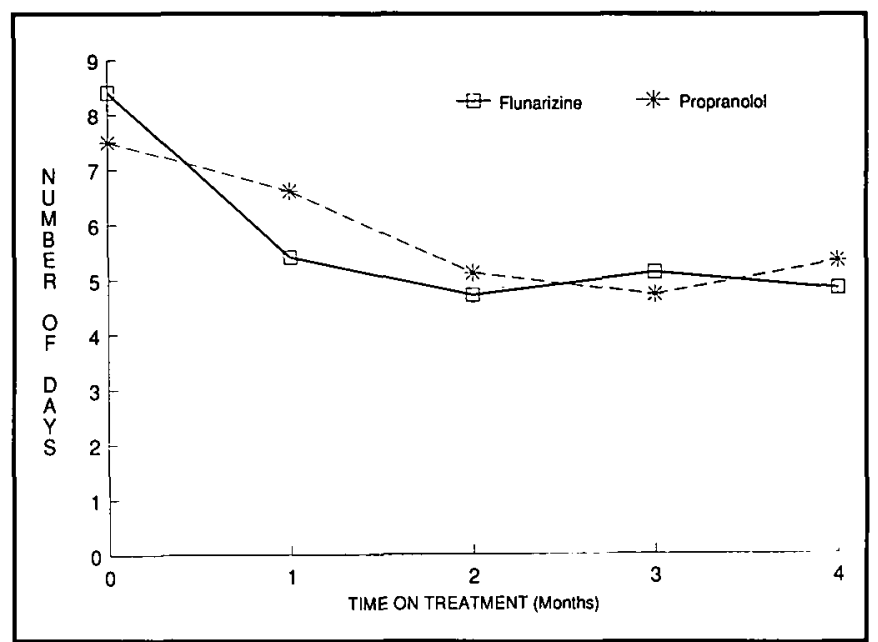

Figure 2 - Mean number of days with headache. 
arms compared to baseline ( $p=0.004$ ) (Figure 3). The decrease in analgesic consumption was statistically similar in both treatment groups.

Body Mass Index (BMI) was calculated for each patient. ${ }^{18}$ BMI increased to a statistically significant extent among patients taking either flunarizine (baseline 24.3 to termination $25.3 \mathrm{~kg} / \mathrm{m}^{2}$ ) or propranolol (baseline 25.0 to termination 26.0 $\mathrm{kg} / \mathrm{m}^{2}$ ). The weight gain tended to be greater in the flunarizine group (Figure 4). BMI did not exceed the normal range in either treatment group.

Propranolol treatment was associated with statistically significant decreases in blood pressure (systolic and diastolic) and heart rate (Table 3 ). Flunarizine demonstrated no effect on cardiovascular function.

No clinically relevant abnormalities were identified in the standard biochemistry, haematology or urinalysis laboratory tests.

A total of 182 unique (no intra-patient duplication) adverse experiences was reported during the active treatment phase by 33 patients taking flunarizine and 36 patients taking propranolol. No obvious between treatment differences in severity or drug relatedness were observed. Propranolol therapy was associated with a noticeably greater incidence of: dizziness, hypoaesthesia, insomnia, agitation, nausea, diarrhoea and dyspepsia. By contrast, a preponderance of reports of fatigue and weight gain was seen in the flunarizine-treated group. The incidence of

Table 3: Mean Weighted Duration of Migraine Attack* and Difference From Baseline Scores

\begin{tabular}{|c|c|c|}
\hline \multirow[b]{2}{*}{ Visit } & \multicolumn{2}{|c|}{ Treatment group } \\
\hline & $\begin{array}{l}\text { Flunarizine } \\
\text { Mean (n) SD }\end{array}$ & $\begin{array}{l}\text { Propranolol } \\
\text { Mean (n) SD }\end{array}$ \\
\hline \multicolumn{3}{|c|}{ MEAN SCORES (hours) } \\
\hline Baseline & $12.0(44) 5.3$ & $11.7(45) 5.1$ \\
\hline Month 1 & 12.7 (44) 7.1 & $9.8(45) 5.8$ \\
\hline Month 2 & $12.9(43) 7.3$ & $10.0(43) 7.7$ \\
\hline Month 3 & $12.4(40) 7.6$ & $8.9(40) 7.5$ \\
\hline Month 4 & $12.5(37) 7.7$ & $10.5(39) 7.8$ \\
\hline \multicolumn{3}{|c|}{ DIFFERENCE SCORES (hours) } \\
\hline Final (Completers) & $0.34(37) 8.66$ & $-1.03(39) 8.61$ \\
\hline Last evaluable & $0.22(44) 8.26$ & 0.59 (45) 9.18 \\
\hline
\end{tabular}

*midpoint weight for categorical duration groups) $\times$ (number of attacks of that duration)] / (total number of attacks)

Table 4: Mean Migraine Attack Severity* and Difference From Baseline Scores

\begin{tabular}{|c|c|c|}
\hline \multirow[b]{2}{*}{ Visit } & \multicolumn{2}{|c|}{ Treatment group } \\
\hline & $\begin{array}{l}\text { Flunarizine } \\
\text { Mean (n) SD }\end{array}$ & $\begin{array}{l}\text { Propranolol } \\
\text { Mean (n) SD }\end{array}$ \\
\hline \multicolumn{3}{|l|}{ MEAN SCORES } \\
\hline Baseline & $5.2(44) 1.6$ & $5.2(45) 1.5$ \\
\hline Month & $5.1(44) 2.1$ & $4.6(45) 2.0$ \\
\hline Month & $5.5(43) 2.2$ & $4.2(43) 2.4$ \\
\hline Month & $4.8(40) 2.0$ & $4.2(40) 2.7$ \\
\hline Month & $5.3(37) 2.6$ & $4.7(39) 2.6$ \\
\hline \multicolumn{3}{|l|}{ DIFFERENCE SCORES } \\
\hline Final (Completers) & $0.00(37) 2.68$ & $-0.53(39) 2.50$ \\
\hline Last evaluable & $-0.02(44) 2.68$ & $-0.20(45) 2.95$ \\
\hline
\end{tabular}

*severity grading scale of 1 (mild) - 10 (excruciating) depression was comparable in both treatment groups $(3.3 \%)$. There was no evidence of extrapyramidal symptoms in the flunarizine group. Three $(7 \%)$ patients taking flunarizine and 5 (11\%) patients taking propranolol withdrew prematurely as a result of adverse events (Table 4 ).

\section{Discussion}

This double-blind study was designed to detect differences in the efficacy and safety profiles of two drugs commercially available in Canada for the prophylaxis of migraine headache: flunarizine (Sibelium) and propranolol (Inderal). A comprehensive and conservative between-treatment (across-time and endpoint) as well as a within-treatment (endpoint) approach to the statistical analysis was taken in order to validate and strengthen the credibility of clinical conclusions drawn from this active control trial.

The results of this study confirm the efficacy of both flunarizine and propranolol in the prophylactic management of migraine with and without aura as has been established in previous controlled investigations. ${ }^{10-16.19 .20}$ The onset and maintenance of antimigraine activity as well as the magnitude of response obtained with flunarizine treatment were at least comparable to propranolol, the current standard of therapy. On several key

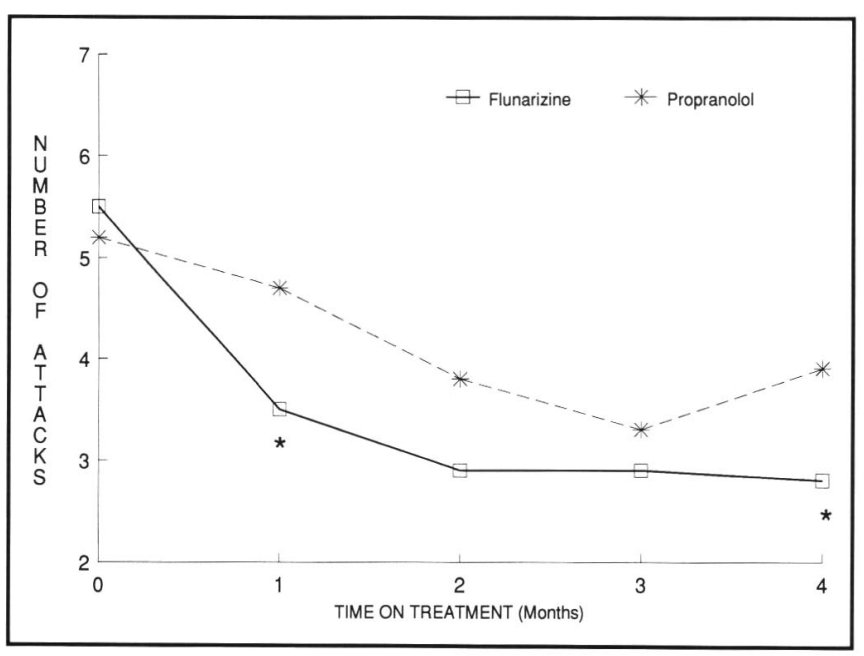

Figure 1-Mean number of migraine attacks.

* statistically significantly fewer attacks for flunarizine.

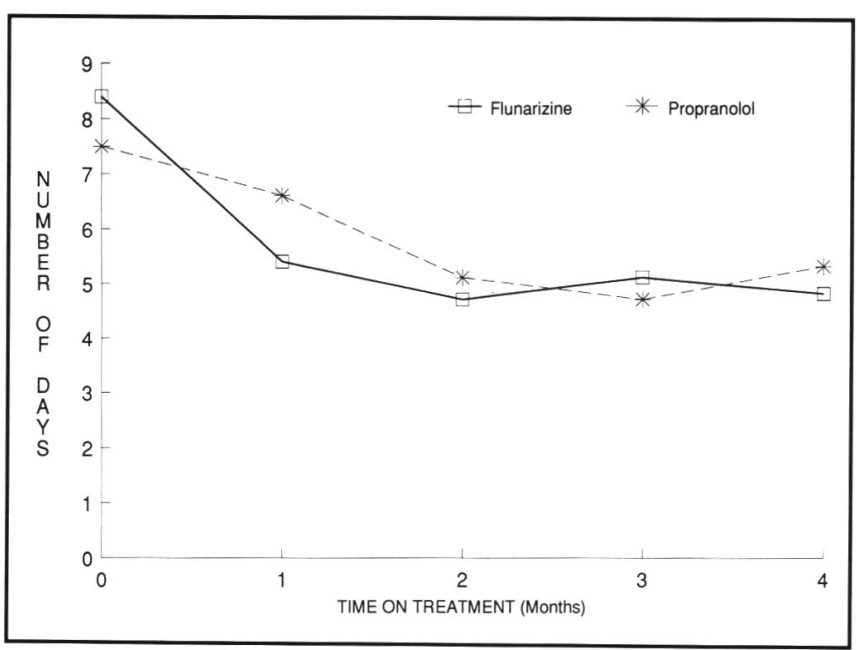


efficacy measures, the response to flunarizine clinically surpassed that to propranolol. Statistically, flunarizine was favoured in the between-treatment comparisons. However, statistical separation of treatment groups was not found frequently; this inability to detect consistent differences is likely a reflection of the small sample size and high degree of variability associated with many of the subjective efficacy assessments.

Overall, the response to treatment was greater in the patients taking flunarizine with a positive response being reported in $67 \%$ of these patients compared to $51 \%$ among patients treated with propranolol. These response rates are less than those described in the literature and are perhaps due to a selection bias for refractory patients referred to our specialist clinics. Analysis of response by type of migraine revealed that efficacy in patients with migraine with aura was comparable between groups (flunarizine 59\%, propranolol $61 \%$ ) whereas patients with migraine without aura responded better to flunarizine (73\%) than to propranolol (44\%). Thus, to some extent, the trend to superiority in the flunarizine group was carried by the migraineurs without aura. Although of interest, these observations are certainly not conclusive in that the small sample size of this study results in low frequency cells in a Chi Square and precludes definitive interpretation of the data.

The safety profiles of flunarizine and propranolol observed in this study were predictable. Weight gain was the most notable event for flunarizine but was also observed in the propranololtreated subjects. This effect may have been due to improvement in the migraine attack rate or to a pharmacological mechanism. Importantly, mean BMI did not exceed the upper limit of normal in either treatment group. On the basis of propranolol's wellestablished effect on the cardiovascular system, ${ }^{21}$ the depressant effect on pulse and blood pressure observed with this drug was its most notable side effect (Table 5). Consistent with its lack of affinity for cardiovascular slow channels, flunarizine had no effect on cardiovascular functions. The incidence of depression, an effect which has been reported with both drugs, ${ }^{22.23}$ was comparable and low in both groups. Drug-induced extrapyramidal effects which have been described for flunarizine, ${ }^{23.24}$ were not observed in this study.

It is concluded that flunarizine and propranolol are each effective and well-tolerated medications for the prophylactic treatment of migraine headache. Flunarizine is at least as effective and may be better tolerated than propranolol. Given the suboptimal efficacy, intolerable side effects, and risk of rebound headache associated with agents available for acute attacks as well as the limitations of traditional prophylactic agents for migraine, research continues in this area to identify new compounds with antimigraine activity that are both effective and well-tolerated. The recent introduction of flunarizine represents

Table 5: Effect of Treatment on Cardiovascular Function at Termination. Mean Difference From Baseline Scores

\begin{tabular}{lcc}
\hline \hline $\begin{array}{l}\text { Parameter } \\
\text { (Mean } \pm \text { SD) }\end{array}$ & \multicolumn{2}{c}{ Treatment group } \\
Propranolol
\end{tabular}

*statistically significant decrease from baseline
Table 6: Adverse Events Associated With Premature Discontinuation

\begin{tabular}{lcl}
\hline \hline Treatment group & Number of Patients & Adverse event \\
\hline Flunarizine & 3 & Depression \\
& & Weight gain \\
& & Fatigue \\
Propranolol & 5 & Bloating / Weight gain \\
& & Bloating \\
& Rash \\
& Increased headache \\
& Increased headache / \\
& Depression \\
\hline
\end{tabular}

an important therapeutic option now available to the Canadian practitioner in the pharmacological management of migraine patients where existing alternatives are often unsatisfactory.

\section{ACKNOWLEDGEMENTS}

Supported by a grant from Janssen Pharmaceutica Inc., Mississauga, Ontario, Canada. Statistical support of McDougall Scientific (Janet McDougall, MSc, President) is gratefully acknowledged.

\section{REFERENCES}

1. Edmeads JG. Recent advances in pharmacotherapy: Migraine. Can Med Assoc J 1988; 138: 107 - 113.

2. Edmeads JG. Advances in migraine prophylaxis: Introduction. In Proceedings of a symposium at the XXVth meeting of the Canadian Congress of Neurological Sciences. Banff, Alberta: Canadian Congress of Neurological Sciences, June 1990.

3. Anonymous. Inderal $®$ Product Monograph. In: Krogh CME, Gillis MC, Bisson R, eds. Compendium of Pharmaceuticals and Specialties. 26th ed. Toronto: CK Productions, 1991: 575 - 577.

4. Solomon GD. Comparative efficacy of calcium antagonist drugs in the prophylaxis of migraine. Headache $1985 ; 25: 368-371$.

5. Meyer JS, Hardenberg J. Clinical effectiveness of calcium entry in prophylactic treatment of migraine and cluster headaches. Headache 1983; 23: $266-277$.

6. Anonymous. Sibelium $®$ Product Monograph. In: Krogh CME, Gillis MC, Bisson R, eds. Compendium of Pharmaceuticals and Specialties. 26th ed. Toronto: CK Productions, 1991: 1106 1107.

7. Vanhoutte PM, Paoletti R. The WHO classification of calcium antagonists. Trends Pharmacol Sci 1987;

8. Holmes B, Brogden RN, Heel RC, et al. Flunarizine: a review of its pharmacodynamic and pharmacokinetic properties and therapeutic use.Drugs 1984; 27(1): 6 - 44 .

9. Todd PA, Benfield P. Flunarizine: a reappraisal of its pharmacological properties and therapeutic use in neurological disorders. Drugs 1989; 38(4): 481 - 499.

10. Sorensen PS, Hansen K, Olesen J. A placebo-controlled, doubleblind, cross-over trial of flunarizine in common migraine. Cephalalgia 1986: 6: 7 - 14 .

11. Louis P. A double-blind placebo-controlled prophylactic study of flunarizine (Sibelium()) in migraine. Headache 1981; 21: 235 239.

12. Louis P, Spierings ELH. A comparison of flunarizine (Sibelium $\circledast$ ) and pizotifen (Sandomigran $($ ) in the treatment of migraine. A double-blind study. Cephalalgia 1982; 2: 197 - 203.

13. Steardo L, Marano E, Barone P, et al. Prophylaxis of migraine attacks with a calcium-channel blocker: flunarizine versus methysergide. J Clin Pharmacol 1986; 26: 524 - 528.

14. Lücking $\mathrm{CH}$, Oestreich W, Schmidt R, et al. Flunarizine vs. propranolol in the prophylaxis of migraine: two double-blind comparative studies in more than 400 patients. Cephalalgia $1988 ; 8$ (Suppl 8): $21-26$. 
15. Ludin HP. Flunarizine and propranolol in the treatment of migraine. Headache 1989;29:218-223.

16. Shimell CJ, Fritz VU, Levien SL. A comparative trial of flunarizine and propranolol in the prevention of migraine. S Afr Med $J$ 1990; 77: $75-78$.

17. Miles-McDermott NJ, Federer WT, Meredith MP, Feng ZD. The analysis of covariance for split unit and repeated measures experiments using the GLM procedure in SAS/STAT. Proceedings of the Thirteenth Annual SAS Users Group International (SUGI 13), SAS Institute Inc., Cary, North Carolina, 1988.

18. Health Services and Promotion Branch, Health and Welfare Canada. Promoting healthy weights: a discussion paper. Published by authority of the Minister of National Health and Welfare, Health and Welfare Canada. Ottawa: Minister of Supply and Services Canada, 1988.

19. Rosen JA. Observations on the efficacy of propranolol for the proplyaxis of migraine. Ann Neurol 1983; 13: 92 - 93 .
20. Diamond S, Kudrow L, Steven J et al. Long-term study of propranolol in the treatment of migraine. Headache 1982; 22: $268-271$.

21. Hoffmann BB, Lefkowitz RJ. Adrenergic receptor antagonists: II. adrenergic receptor antagonists. In: Goodman Gilman A, Rall TW, Nies AS, Taylor P, eds. Goodman and Gilman's The pharmacological basis of therapeutics. 8th ed. Toronto: Pergamon Press, 1990: 229 - 241.

22. Olerud B, Gustavsson CL, Furberg B. Nadolol and propranolol in migraine management. Headache 1986; 26: 490 - 493.

23. Lugaresi A, Montagna P, Gallassi $R$ et al. Extrapyramidal syndrome and depression induced by flunarizine. Eur Neurol 1988; 28: 208 - 211 .

24. Benvenuti $\mathrm{F}$, Baroni $\mathrm{A}$, Bandinelli $\mathrm{S}$, et al. Flunarizine - induced Parkinsonism in the elderly. J Clin Pharmacol 1988; 26: 600 - 608. 